KANSAS JOURNAL of MEDICINE

\section{Trends in Internet Safety Education by Healthcare Providers}

Gary King, M.D., Thuy Bui, MPH, Julian Dedeaux, Ph.D., Carolyn R. Ahlers-Schmidt, Ph.D., Kari Harris, M.D. University of Kansas School of Medicine-Wichita, Wichita, KS Department of Pediatrics

Received Oct. 29, 2020; Accepted for publication July 15, 2021; Published online Nov. 5, 2021 https: doi.org 10.17161 kim.voll4.1480.5

\section{ABSTRACT}

Introduction. The purpose of this study was to explore healthcare provider training, comfort, and provision of internet safety counseling. Prior research has demonstrated increased parental concern regarding the pervasive access to the internet by children, including the potential impacts of risky internet behavior and adverse media exposure.

Methods. A self-reported survey was provided to a convenience sample of 31 healthcare providers during a mental health training seminar. Responses were analyzed using descriptive statistics.

Results. Internet safety counseling, especially regarding risky online behavior, was not a focal point of provider-patient interaction in the sample population. This finding was reinforced with more than half of the respondents indicating that they infrequently or never provide internet safety counseling $(n=17,56 \%)$. While research has placed an emphasis on the importance of discussing the risks of exposure to violence, drugs, and sexually explicit media online, this study found that the topics most often discussed were setting time limits (77\%), limiting access to media devices (67\%), and supervising internet use (50\%). This may be due in part to the fact that most respondents $(\mathrm{n}=17,57 \%)$ reported never receiving training on internet safety counseling.

Conclusions. Overall, significant deficits were identified in internet safety counseling training for professionals and provision of education for families. These finding were inconsistent with the American Academy of Pediatrics recommendations around media use counseling and a point of urgent concern given the increasing time spent on media devices, particularly during the COVID pandemic.

\section{Kans.J Med 2021;14:273-276}

\section{INTRODUCTION}

Internet access is nearly ubiquitous to American youth with access becoming virtually unlimited through mobile devices. The COVID pandemic has encouraged social distancing, and as a result, children's access to the internet is becoming increasingly pervasive. As of 2015, 92\% of adolescents go online daily., Approximately $75 \%$ of adolescents own a smart phone with $25 \%$ reporting they are online "almost constantly". In addition, $76 \%$ of adolescents maintain at least one social media profile. This prevalence is not only relevant in adolescent youth. Nearly all homes with small children (98\%) own a mobile device, an increase from $75 \%$ in 2013 and $52 \%$ in $2011 .{ }^{3}$ Further, $50 \%$ of five-yearold children go online daily and nearly $75 \%$ of four-year-old children have their own mobile device., Although data were lacking on media use during the COVID pandemic, these prior statistics supported the
American Academy of Child and Adolescent Psychiatry's (AACAP) concern that quarantined youth have unprecedented access to potentially harmful media content and that risk needs to be mitigated. ${ }^{6}$

Parents were concerned about potential adverse impacts of the internet on their children, most notably the impact of exposure to violent and sexual content. ${ }^{7}$ Parental concerns were placed appropriately given research has shown poor outcomes of child exposure to risky behaviors. Specifically, children who consume media rich in alcohol advertisements were more likely to initiate use. ${ }^{8-10}$ The same influential effect has been shown for sexually explicit media, including pornography. ${ }^{11,12}$ These risks can be applied to other online safety concerns such as cyberbullying and increased risk of suicidal ideation. ${ }^{13}$ To mitigate these risks, trusted adults need to engage in conversation with youth emphasizing media safety. ${ }^{14,15}$ Taken together, parental mediation of media use has been shown to decrease risky behaviors. ${ }^{16,17}$ More than ever, parents should be intentional about helping youth develop positive media habits. This can be done by modeling healthy behaviors, setting limits, and co-viewing.?

In addition to parents, healthcare providers play an important role in delivering internet safety education to youth..$^{15,18,19}$ Parents trust healthcare providers to provide appropriate recommendations for the health and well-being of their children. The American Academy of Pediatrics (AAP) has released a policy statement, "Media Use in School-Aged Children and Adolescents", outlining best practices for parents and pediatric healthcare providers. ${ }^{18}$ This statement included information on the AAP's Family Media Plan, which can be an asset to parents during quarantine as well as non-quarantine times. Healthcare providers have a unique opportunity to support parents in providing resources and anticipatory guidance on internet safety. Despite this policy statement, only one in five parents were aware of the AAP's recommendation, indicating a gap in communication between parents and pediatric healthcare providers. Although pediatricians have been tasked with educating parents on this topic, to what extent this happens remained unclear.

Three study objectives were investigated:

1. To explore the extent and type of counseling provided by healthcare providers on internet safety.

2. To explore the type and extent of training that healthcare providers have received on internet safety, their comfort level, and barriers to providing counseling.

3. To determine if internet safety counseling differs between provider demographic groups.

\section{METHODS}

Prior to engaging in the study, Institutional Review Board approval was obtained through University of Kansas School of Medicine-Wichita Human Subjects Committee. An anonymous, self-reported, 14-item survey was developed to capture information related to healthcare provider demographics, training, and experience with internet safety counseling. Prior to use, the survey was reviewed by an expert panel for readability.

Healthcare providers attending a local mental health training seminar in late 2018 were asked to participate in this study. Participation was voluntary, informed consent was obtained, and no incentives were 
provided. Participants included community and academic physicians, resident physicians, and physician extenders (i.e., nurse practitioners, physician assistants) who provide primary care to children. Non-practicing healthcare providers and providers who do not serve children were excluded from the study.

Data were entered into the encrypted and HIPAA compliant REDCap ${ }^{\varpi}$ online data capture application. Descriptive statistics were calculated from the database.

\section{RESULTS}

Of 31 potential participants, a total of $30(n=30,97 \%)$ completed the survey. Of the 30 respondents, most were pediatricians $(\mathrm{n}=24$, $80 \%$ ), female ( $\mathrm{n}=21,70 \%)$, and had been in practice for an average of 10.5 years ( $\mathrm{SD}=9.8$; Table 1 ). The majority of providers characterized their practice as urban $(n=20,67 \%)$, and cared for children in all age ranges $(\geq 80 \%)$. The mean provider's age was 42.3 years $(\mathrm{SD}=9.9)$. Most providers reported having children of their own, with only 17\% (n $=5$ ) reporting they had no children. No statistically significant correlations were found between provider demographics and provider delivery of internet safety counseling.

Most providers $(\mathrm{n}=17 ; 57 \%)$ reported having never received training on internet safety counseling. Of those who had received training ( $\mathrm{n}=$ $13 ; 43 \%$ ), independent study and informal training were most common, followed by in-person lectures, and online courses (Table 2). Few reported the adequacy of their training as good and none as very good. Regardless of training, few respondents $(n=8 ; 27 \%)$ felt comfortable or very comfortable with their knowledge on internet safety. An equal amount $(\mathrm{n}=8 ; 27 \%)$ of providers reported that they felt uncomfortable with their level of knowledge.

The majority $(\mathrm{n}=17 ; 57 \%)$ of respondents reported providing internet safety counseling during well child and adolescent visits infrequently or never. When counseling was provided, only $3 \%(n=1)$ waited to initiate counseling until the patients started high school. Topics discussed most often by providers included setting time limits $(\mathrm{n}=23 ; 77 \%)$, limiting access to media devices $(\mathrm{n}=20 ; 67 \%)$, and supervising internet use ( $\mathrm{n}=15 ; 50 \%$; Figure 1). Topics involving avoidance of risky internet behavior were discussed routinely by $37 \%(\mathrm{n}=11)$ of respondents and risks of adverse internet exposure were discussed only by $27 \%(n=8)$.

Ninety percent of respondents $(\mathrm{n}=27)$ indicated time constraint as a barrier to providing internet safety counseling, followed by $47 \%$ ( $\mathrm{n}=$ 14) having limited knowledge on the topic, $40 \%(\mathrm{n}=12)$ forgetting to provide counseling, and 30\% $(\mathrm{n}=9)$ having a lack of resources.

\section{DISCUSSION}

The results of this study demonstrated provider training, comfort, and delivery of internet safety counseling were less than optimal with over half of providers never or infrequently providing counseling. Only $20 \%$ of providers reported counseling most of the time. Parents have reported internet safety as a top concern, specifically regarding exposure to sexual and violent content, or risky internet behaviors. ${ }^{37}$ While providers in this study reported discussing risky internet behaviors, the rates of these discussions were at lower frequency than other topics, such as setting time limits. This result illustrated a gap in care, as media topics that parents were most concerned about were being discussed infrequently by their child's healthcare provider.
KANSAS JOURNAL of MEDICINE

INTERNET SAFETY EDUCATION

continued.

Table 1. Descriptive demographics of sample population.

\begin{tabular}{|l|c|c|}
\hline & M & SD \\
\hline Age & 42.3 & 9.9 \\
\hline Years in practice & 10.5 & 9.8 \\
\hline & n & $\%$ \\
\hline Gender & & \\
\hline Males & 9 & 30 \\
\hline Females & 21 & 70 \\
\hline Geographic region & & \\
\hline Rural (population $<50 \mathrm{~K})$ & 9 & 30 \\
\hline Urban (population $>50 \mathrm{~K})$ & 20 & 67 \\
\hline Missing & 1 & 3 \\
\hline Specialty & & \\
\hline Pediatrics & 24 & 80 \\
\hline Family Medicine & 5 & 17 \\
\hline Other & 1 & 3 \\
\hline Age groups seen & & \\
\hline Infants/young children $(0-5$ years $)$ & 26 & 87 \\
\hline School aged (6 - 11 years) & 26 & 87 \\
\hline Adolescents (12 - 17 years) & 23 & 77 \\
\hline Providers as parents & & \\
\hline Infants $/$ young children $(0-5$ years $)$ & 9 & 30 \\
\hline School aged $(6-11$ years) & 13 & 43 \\
\hline Adolescents $(12-17$ years $)$ & 12 & 40 \\
\hline Adult children $(18$ years $)$ & 8 & 27 \\
\hline None & 5 & 17 \\
\hline
\end{tabular}

The optimal time for introduction of internet safety to children is not known. Nevertheless, many key stakeholders, including parents, adolescents, teachers, and healthcare providers agreed that internet safety counseling should be started at a young age, between six to eight years. ${ }^{20}$ However, given the increasing prevalence of very young children accessing the internet regularly, ${ }^{3-5}$ it would be prudent for internet safety education to be introduced with the onset of internet use. This study found only $13 \%$ of providers initiated conversations about internet safety with the parents of very young children, and $33 \%$ start during elementary school.

The AAP has recognized that pediatricians have an important role in providing guidance to patients and families regarding internet safety in their policy statement "Media Use in School-Aged Children and Adolescents". ${ }^{18}$ In this statement, the AAP emphasized the development and use of a personalized Family Media Use Plan that considers the child's age, health, temperament, developmental stage, and individual needs. The use of this tool has been encouraged during the COVID pandemic. ${ }^{20}$ This study found that the primary barriers to providing internet safety counseling center around time constraints and lack of provider knowledge on the topic. Increasing awareness of the important role providers have in mitigating risks associated with unsafe internet 
KANSAS JOURNAL of MEDICINE

INTERNET SAFETY EDUCATION

continued.

use may reduce these barriers. Providers should be offered resources and education on adverse media exposure, including ways to initiate discussions with families. Some authors suggested expanding the HEADS (Home; Education/Employment; Activities; Drugs/Depression/Diet; Sex/Suicide/Safety) psychosocial history-taking pneumonic as a useful tool to include elements of media use, thereby assisting providers to engage patients and families on discussions of internet safety. ${ }^{21,22}$

Table2. Physician trainingand practice on internetsafety counseling.

\begin{tabular}{|c|c|c|}
\hline Training format & $\mathbf{n}$ & $\%$ \\
\hline Independent study & 9 & 30 \\
\hline Informal setting & 6 & 20 \\
\hline In-person lecture & 5 & 17 \\
\hline Online training & 4 & 13 \\
\hline None & 17 & 57 \\
\hline \multicolumn{3}{|l|}{ Adequacy of training } \\
\hline Very good & 0 & 0 \\
\hline Good & 4 & 13 \\
\hline Adequate & 7 & 23 \\
\hline Poor & 2 & 7 \\
\hline Very poor & 0 & 0 \\
\hline Did not receive training & 13 & 43 \\
\hline Missing & 4 & 13 \\
\hline \multicolumn{3}{|l|}{ Comfort with knowledge } \\
\hline Very comfortable & 2 & 7 \\
\hline Comfortable & 6 & 20 \\
\hline Neutral & 14 & 47 \\
\hline Uncomfortable & 8 & 27 \\
\hline Very uncomfortable & 0 & 0 \\
\hline \multicolumn{3}{|l|}{ Frequency of practice } \\
\hline Always & 0 & 0 \\
\hline Most of the time & 6 & 20 \\
\hline Sometimes & 7 & 23 \\
\hline Infrequently & 13 & 43 \\
\hline Never & 4 & 13 \\
\hline \multicolumn{3}{|l|}{ Age of initiation of internet safety counseling } \\
\hline High school & 1 & 3 \\
\hline Middle school & 8 & 27 \\
\hline Elementary school & 10 & 33 \\
\hline Pre-school & 3 & 10 \\
\hline Infant/toddler & 1 & 3 \\
\hline Do not provide internet safety counseling & 6 & 20 \\
\hline
\end{tabular}




\section{CONCLUSIONS}

Healthcare providers have a unique opportunity to support parents and children in providing resources and anticipatory guidance on internet safety. Nonetheless, significant deficits were identified in provider training, comfort, and provision of internet safety counseling for families. Further studies need to be performed to evaluate the significance of these findings on a wider scale. Providers need to be cognizant of their role in mitigating risk associated with unsafe media exposure by offering internet safety counseling to patients and their families.

\section{ACKNOWLEDGEMENTS}

We would like to thank the University of Kansas School of Medicine-Wichita Department of Pediatrics and The REACH Institute for allowing us to survey the attendees of their mental health seminar. We also acknowledge Dr. Julian Dedeaux for his assistance in bringing this manuscript to completion.

\section{REFERENCES}

${ }^{1}$ Anderson M. Parents, teens and digital monitoring. January 7,2016. http:// www.pewInternet.org/2016/01/07/parents-teens-and-digital-monitoring. Accessed October 2, 2018.

2 Lenhart A. Teens, social media, and technology overview. April 9, 2015. http://www.pewInternet.org/2015/04/09/teens-social-media-technology-2015. Accessed October 2, 2018.

${ }^{3}$ Common Sense. The Common Sense census: Media use by kids age zero to eight. 2017. https://www.commonsensemedia.org/sites/default/files/ uploads/research/csm_zerotoeight_fullreport_release_2.pdf. Accessed October 2, 2018].

${ }^{4}$ Kabali HK, Irigoyen MM, Nunez-Davis R, et al. Exposure and use of mobile media devices by young children. Pediatrics 2015; 136(6):1044-1050. PMID: 26527548.

${ }^{5}$ Swindle TM, Ward WL, Whiteside-Mansell L, Bokony P, Pettit D. Technology use and interest among low-income parents of young children: Differences by age group and ethnicity. J Nutr Educ Behav 2014; 46(6):484490. PMID: 25087748.

${ }^{6}$ American Academy of Child and Adolescent Psychiatry. Media habits during COVID-19: Children and teens on screens in quarantine. https:// www.aacap.org/App_Themes/AACAP/Docs/resource_libraries/covid-19/ Screen-Time-During-COVID.pdf. Accessed May 18, 2020.

7 C.S. Mott Children's Hospital. Mott Poll Report. Bullying and internet safety are top health concerns for parents. August 21, 2017. http://mottpoll. org/reports-surveys/bullying-and-Internet-safety-are-top-health-concerns-parents. Accessed November 12, 2020.

8 Litt DM, Stock ML. Adolescent alcohol related risk cognitions: The roles of social norms and social networking sites. Psychol Addict Behav 2011; 25(4):708-713. PMID: 21644803.

9 Robinson TN, Chen HL, Killen JD. Television and music video exposure and risk of adolescent alcohol use. Pediatrics 1998; 102(5):E54. PMID: 9794984.

10 Winpenny EM, Marteau TM, Nolte E. Exposure of children and adolescents to alcohol marketing on social media websites. Alcohol Alcohol 2014; 49(2):154-159. PMID: 24293506.

11 Ashby SL, Arcari CM, Edmonson MB. Television viewing and risk of sexual initiation by young adolescents. Arch Pediatr Adolesc Med 2006; 160(4):375-380. PMID: 16585482.

${ }^{12}$ Bailin A, Milanaik R, Adesman A. Health implications of new age technologies for adolescents: A review of the research. Curr Opin Pediatr 2014; 26(5):605-619. PMID: 25160783.

${ }^{13}$ Litwiller BJ, Brausch AM. Cyber bullying and physical bullying in adolescent suicide: The role of violent behavior and substance use. J Youth Adolesc 2013; 42(5):675-684. PMID: 23381779.

${ }^{14}$ Coyne SM, Radesky J, Collier KM, et al. Parenting and digital media. Pediatrics 2014; 40(suppl 2):S112-S116. PMID: 29093044.

${ }_{15}$ Harris KR, Hopper MT. Preventing teen pregnancy at pre-adolescence. In: Akella D (Ed.). Socio-cultural influences on teenage pregnancy and contemporary prevention measures. Hershey, PA: IGI Global, 2019. pp. 166-188. ISBN: 1522561080.

${ }^{16}$ Collier KM, Coyne SM, Rasmussen EE, et al. Does parental mediation of media influence child outcomes? A meta-analysis on media time, aggression, substance use, and sexual behavior. Dev Psychol 2016; 52(5):798-812. PMID: 26914217.
KANSAS JOURNAL of MEDICINE INTERNET SAFETY EDUCATION

\section{continued.}

17 Starr CR, Ferguson GM. Sexy dolls, sexy grade-schoolers? Media and maternal influences on young girls' self-sexualization. Sex Roles 2016; 67(78):463-476.

${ }_{18}$ Council on Communications and Media. Media use in school-aged children and adolescents. Pediatrics 2016; 138(5):e20162592. PMID: 27940794.

19 Moreno MA, Egan KG, Bare K, Young HN, Cox ED. Internet safety education for youth: Stakeholder perspectives. BMC Public Health 2013; 13:543. PMID: 23738647.

20 American Academy of Pediatrics. Teens \& COVID-19: Challenges and opportunities during the outbreak. June 5, 2020. https://www.healthychildren.org/English/health-issues/conditions/chest-lungs/Pages/ Teens-and-COVID-19.aspx. Accessed November 12, 2020.

${ }^{21}$ Contemporary Pediatrics. HEEADSSS 3.0: The psychosocial interview for adolescents updated for a new century fueled by media. January 1. 2014 . https://www.contemporarypediatrics.com/view/heeadsss-30-psychosocial-interview-adolescents-updated-new-century-fueled-media. Accessed November 12, 2020.

${ }^{22}$ Norris ML. HEADSS up: Adolescents and the internet. Pediatr Child Health 2007; 12(3):211-216. PMID: 19030361.

Keywords: internet, primary care, pediatrics, social media 